\title{
Tuning intermetallic electronic coupling in polyruthenium systems via molecular architecture
}

\author{
SANDEEP GHUMAAN and GOUTAM KUMAR LAHIRI* \\ Department of Chemistry, Indian Institute of Technology - Bombay, Powai, Mumbai 400076 \\ e-mail: lahiri@chem.iitb.ac.in
}

\begin{abstract}
A large number of polynuclear ruthenium complexes encompassing selective combinations of spacer (bridging ligand, BL) and ancillary (AL) functionalities have been designed. The extent of intermetallic electronic communication in mixed-valent states and the efficacy of the ligand frameworks towards the tuning of coupling processes have been scrutinised via structural, spectroelectrochemical, EPR, magnetic and theoretical investigations. Moreover, the sensitive oxidation state features in the complexes of non-innocent quinonoid bridging moieties have also been addressed.
\end{abstract}

Keywords. Polynuclear ruthenium complexes; mixed valency; electronic coupling; spectroelectrochemistry; DFT calculations.

\section{Introduction}

Bridging ligand (BL) induced intermetallic electronic coupling in polyruthenium systems has been the focus of continuous development ${ }^{1}$ since the revolutionary discovery of pyrazine-mediated strong coupling between the ruthenium centres in the mixed valent state of $\left[\left(\mathrm{NH}_{3}\right)_{5} \mathrm{Ru}^{\mathrm{II}}(\mu \text {-pyrazine }) \mathrm{Ru}^{\mathrm{III}}\left(\mathrm{NH}_{3}\right)_{5}\right]^{5+} .{ }^{2}$ Intermetallic coupling in polynuclear systems finds applications in designing molecular electronic devices ${ }^{3}$ such as molecular wires, semi-conductors, rods etc. Moreover, mixed-valent species have direct relevance in biological systems ${ }^{4}$ as well as being important from the perspective of theoretical studies on electron-transfer kinetics. ${ }^{5}$ Bridging function-mediated intermetallic communication usually takes place in two different pathways primarily depending on the electronic nature of the spacer (BL). For a $\pi$-acceptor type of neutral BL it follows an electron-transfer mechanism (A), whereas for an electron-donating spacer, the hole-transfer mechanism (B) dominates. ${ }^{6}$

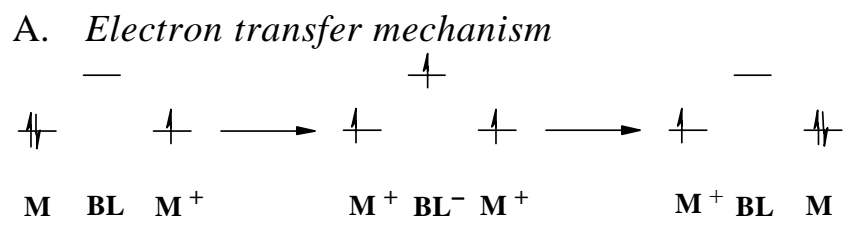

*For correspondence

\section{B. Hole transfer mechanism}

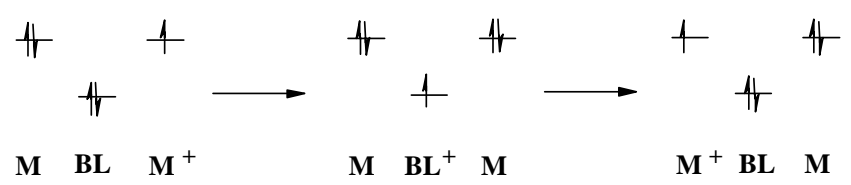

Depending on the extent of coupling, mixed-valent systems can be primarily categorised into three classes: class I, very weak to no coupling; class II, moderate to strong coupling, essentially a valence localised situation; class III, strong to very strong coupling leading to a completely delocalised valence configuration. ${ }^{7}$ Though various well-recognised experimental tools are available to establish the characteristics of the mixed-valent complexes, electrochemical features along with metal $\left(\mathrm{M}^{\mathrm{n}+}\right)-(\mathbf{B L})-$ metal $\left(\mathrm{M}^{\mathrm{n}+1}\right)$ intervalence electronic transition (IVCT) at the low-energy NIR/IR region have been considered to be most effective manifestations in general sense. At the electrochemistry level, the separation in potential $\left(\Delta E^{0}\right)$ between the successive redox processes for a symmetrical diruthenium(II) system provides the comproportionation constant $\left(K_{c}\right)$ value for the equilibrium reaction $(1),{ }^{8}$

$$
\begin{aligned}
& {\left[\mathrm{Ru}^{\mathrm{II}} \mathrm{Ru}^{\mathrm{II}}\right]+\left[\mathrm{Ru}^{\mathrm{III}} \mathrm{Ru^{ \textrm {III } }}\right] \rightleftharpoons 2\left[\mathrm{Ru}^{\mathrm{II}} \mathrm{Ru^{ \textrm {III } }}\right],} \\
& K_{c}=\left[\mathrm{Ru}{ }^{\mathrm{II}} \mathrm{Ru}{ }^{\mathrm{III}}\right]^{2} /\left[\mathrm{Ru}^{\mathrm{II}} \mathrm{Ru^{ \textrm {II } }}\right]\left[\mathrm{Ru^{ \textrm {III } }} \mathrm{Ru}^{\mathrm{III}}\right],
\end{aligned}
$$

where $\Delta G_{c}=-R T\left(\ln K_{c}\right)=-n F\left(\Delta E^{0}\right) ; K_{\mathrm{c}}=10^{(\Delta E / 0.059)}$ for $n=1 ; \Delta E^{0}=$ the separation in potential between 
BL:

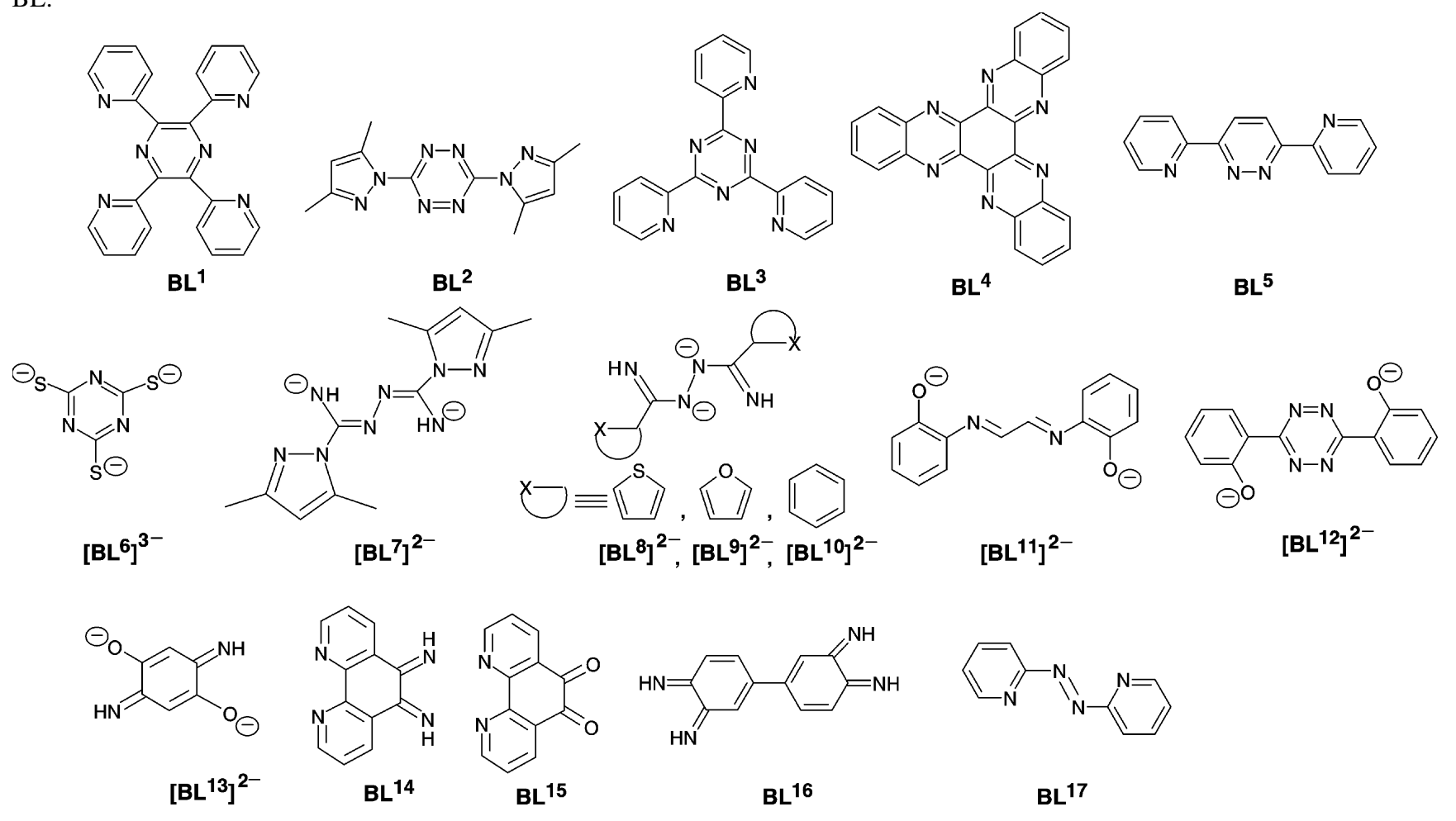

Chart 1.

the two successive redox processes $=E_{2}{ }^{0}\left(\mathrm{M}^{\mathrm{III}} \mathrm{M}^{\mathrm{III}} \rightleftharpoons\right.$ $\left.\mathrm{M}^{\mathrm{II}} \mathrm{M}^{\mathrm{III}}\right)-E_{1}{ }^{0}\left(\mathrm{M}^{\mathrm{II}} \mathrm{M}^{\mathrm{III}} \rightleftharpoons \mathrm{M}^{\mathrm{II}} \mathrm{M}^{\mathrm{II}}\right)$.

$K_{c}$ varies from a statistical value of 4 for completely non-interacting genuine class I systems to $2 \times 10^{24}$ for fully delocalised class III systems. However, the intermediate values of $K_{c}$ introduce challenges in assigning class II, class III or their borderline situation. Usually, at the electrochemical level, class II systems are defined with $K_{c}$ up to $10^{5}$ and higher values of $K_{c} \geq 10^{6}$ provide an indication of class III. Free energy of comproportionation equilibrium $\left(\Delta G_{c},(1)\right)$ consists of several free energy terms, $\Delta G_{s}$ (statistical distribution), $\Delta G_{e}$ (electrostatic repulsion of the positively charged metal ions), $\Delta G_{i}$ (inductive factor due to competitive coordination of the bridging ligand by the metal ions), $\Delta G_{r}$ (resonance exchange), $\Delta G_{a f}$ (antiferromagnetic exchange at the doubly oxidised $\mathrm{Ru}^{\text {III }} \mathrm{Ru}^{\mathrm{III}}$ state) and $\Delta G_{i p}$ (ion-pairing factor). ${ }^{9}$ Therefore the characteristics of the intervalence charge transfer transitions (IVCT), in combination with the electrochemical features, can provide better and simplified understanding about the domain in which a particular mixed-valent system belongs.

For a class II valence localised system, the band width at half-height of the IVCT transition $\left(\Delta v_{1 / 2}\right)$ matches well with the Hush equation ${ }^{10}$ of $\Delta v_{1 / 2}=$ $\left[2.31 \times 10^{3}\left(E_{\max }\right)\right]^{1 / 2}, E_{\max }=$ energy at the maximum height of the IVCT band. However, for a class III system the calculated $\Delta v_{1 / 2}$ value using the Hush equation appears to be much greater than the experimentally derived $\Delta v_{1 / 2}$.

Three kinds of motion, solvent, vibrational and electronic, need to be taken into account in interpreting the band width of IVCT as well as the solvent dependency of the intervalence bands. In class II, the solvent and exchanging electron are localised, whereas in class III, the solvent and vibrations are averaged and the exchanging electron is delocalised, which justifies the broad solvent-dependent and narrow solvent-independent IVCT bands for class II and class III systems respectively.

On the other hand, in the borderline class II-III hybrid system, the solvent is averaged and the exchange electron is localised. Vibrational averaging can also occur depending on the time scale of electron transfer. Thus, class II-III hybrid systems exhibit narrow solvent-independent IVCT bands like delocalised class III systems, though the $K_{c}$ value appears in the typical class II range, $K_{c}<10^{6}{ }^{11}$

A large number of diruthenium complexes incorporating a wide variety of bridging and ancillary ligand combinations have been designed over the past several years in order to understand the built-in 
AL:
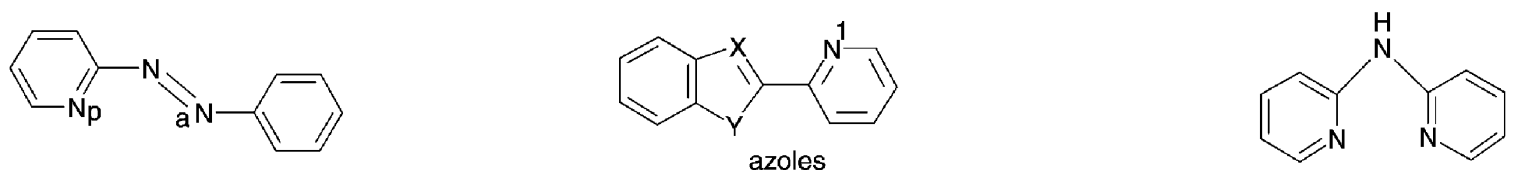

2-Phenylazopyridine (pap, AL $\left.\mathbf{L}^{\mathbf{1}}\right) \quad \mathrm{X}, \mathrm{Y}=\mathrm{N}^{2}, \mathrm{O}\left(\mathbf{A L}^{2}\right) ; \mathrm{N}^{2}, \mathrm{~S}\left(\mathbf{A L}^{3}\right) ; \mathrm{N}^{-2}, \mathrm{~N}\left(\mathbf{A L}^{4}\right) ; \mathrm{N}^{2}, \mathrm{~N}-\mathrm{CH}_{3}\left(\mathbf{A L} \mathbf{L}^{5}\right)$

$2,2^{\prime}-$ dipyridylamine (dpa, $\mathbf{A L}^{6}$ )

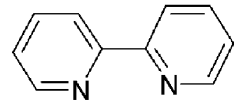

2,2'-bipyridine (bpy, $\mathbf{A L}^{\mathbf{7}}$ )

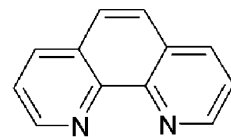

1, 10-phenanthroline (phen, $\mathbf{A L}^{8}$ )

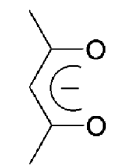

acetylacetonate $\left(\operatorname{acac}, \mathbf{A L}^{\mathbf{9}}\right.$ )

Chart 2.

factors that are responsible for tuning the extent of intermetallic coupling processes in such molecules. In this context, we have also been involved in recent years in looking into the mixed valence characteristics of diruthenium and triruthenium complexes with newer molecular architectures. The present article thus summarises some of our very recent results.

\section{Results and discussion}

Bridging ligands $\left(\mathbf{B L}^{\mathbf{1}}-\mathbf{B} \mathbf{L}^{\mathbf{1 7}}\right.$, chart 1) were chosen for synthesising polyruthenium complexes in combination with a wide variety of ancillary ligands $\left(\mathbf{A} \mathbf{L}^{\mathbf{1}}-\mathbf{A} \mathbf{L}^{\mathbf{9}}\right.$, chart 2).

The deliberations hereafter highlight the effect of a particular combination of bridging (BL) and ancillary (AL) ligands in the complex moieties towards the following primary aspects: (i) the characteristics of the resultant mixed-valent states, and (ii) the preferential involvement of the metal ion or the redox non-innocent bridging ligand towards the accessible electron-transfer processes. The above features have been established via electrochemical, spectroelectrochemical and EPR investigations in combination with structural and DFT calculations in selective cases.

\subsection{Borderline class II-class III mixed-valent systems, $[\mathbf{1}-\mathbf{6}]^{n+}$}

$\mathbf{B L}^{\mathbf{1}}$ bridged diruthenium systems, $[\mathbf{1}-\mathbf{6}]^{n+}[\mathbf{A L}=$ $\operatorname{pap}\left(\mathbf{A} \mathbf{L}^{\mathbf{1}}\right)$; azole: 2-(2-pyridyl)benzoxazole $\left(\mathbf{A L}^{\mathbf{2}}\right), 2$ (2-pyridyl)benzothiazole ( $\left.\mathbf{A L}^{3}\right), 2$-(2-pyridyl)benzimidazolate ( $\mathbf{A L}^{4}$ ), 1-methyl-2-(2-pyridyl)- $1 H$-benzimidazole $\left(\mathbf{A} \mathbf{L}^{\mathbf{5}}\right)$; dpa $\left(\mathbf{A} \mathbf{L}^{\mathbf{6}}\right)$ ] exhibit $K_{c}$ values, $7.9 \times 10^{3}, 3.8 \times 10^{4}, 5.6 \times 10^{4}, 2.6 \times 10^{4}, 2.6 \times 10^{4}$, $2.7 \times 10^{6}$ respectively. ${ }^{12}$ Thus, simply based on $K_{c}$ values $[\mathbf{1}-\mathbf{3}, \mathbf{5}]^{3+} /[\mathbf{4}]^{+} /$and $[6]^{3+}$ can be defined as valence localised class II and class III mixed-valent systems, respectively. However, IVCT transitions in each case of $[\mathbf{1}-\mathbf{3}, \mathbf{5}]^{3+} /[\mathbf{4}]^{+}$provide much narrower profiles (e.g. for $[\mathbf{1}]^{3+}$, the calculated $\Delta v_{1 / 2}$ value of the IVCT band using Hush equation $=3500 \mathrm{~cm}^{-1}$ and the experimentally observed $\Delta v_{1 / 2}=1650 \mathrm{~cm}^{-1}$ ) compared to that expected from a typical class II system according to the Hush equation. In case of $[6]^{3+}$, on the other hand, both $K_{c}$ and IVCT characteristics $\left[K_{c}=2.7 \times 10^{6}\right.$ and $\Delta v_{1 / 2}$ (calculated) $=$ $3680 \mathrm{~cm}^{-1}>\Delta v_{1 / 2}$ (experimental) $\left.=1390 \mathrm{~cm}^{-1}\right]$ are straightaway in favour of the delocalised class III system. The observed anomaly between the electro-
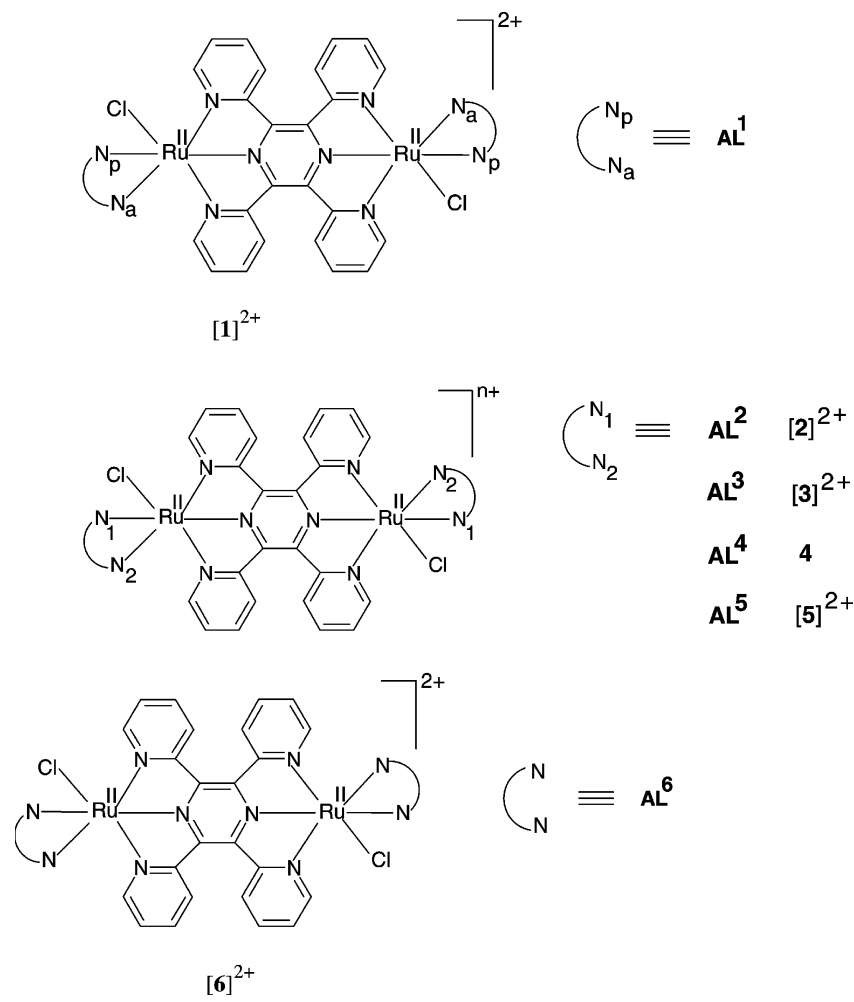
chemical results ( $K_{c}$ implies class II behaviour) and intervalence characteristics (IVCT favours class III behaviour) in $[\mathbf{1}-\mathbf{3}, 5]^{3+} /[\mathbf{4}]^{+}$can be addressed in terms of borderline class II-class III mixed-valent systems.

\subsection{Absence of IVCT transition inspite of strong electrochemical coupling $\left(K_{c}\right)$ in $[\mathbf{7}-\mathbf{1 0}]^{n+}$}
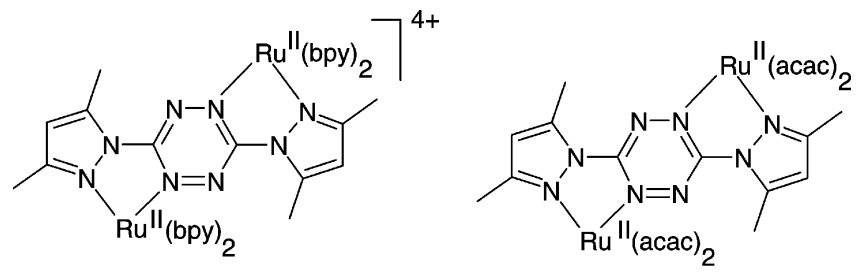

$[7]^{4+}$
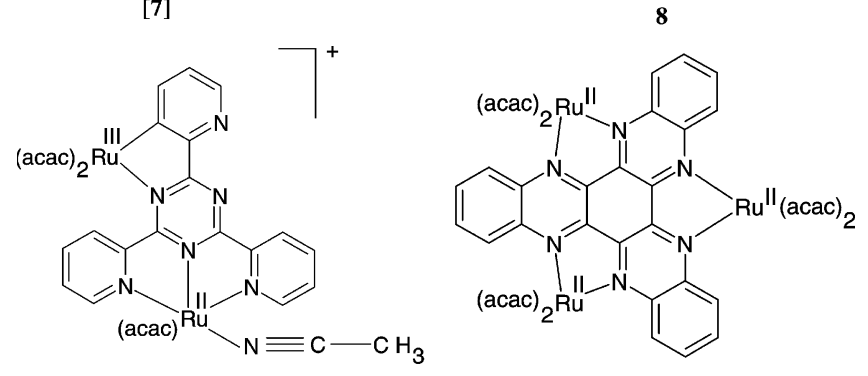

$[9]^{+}$ observed for both the mixed-valent $\mathrm{Ru}^{\mathrm{II}} \mathrm{Ru}{ }^{\mathrm{II}} \mathrm{Ru}{ }^{\mathrm{III}}$ $\left([\mathbf{1 0}]^{+}\right)$and $\mathrm{Ru}^{\mathrm{II}} \mathrm{Ru}^{\mathrm{III}} \mathrm{Ru}^{\mathrm{III}}\left([\mathbf{1 0}]^{2+}\right)$ states in spite of reasonably large $K_{c}$ values of $10^{5 \cdot 7}$ and $10^{8}$ respectively. The absence of IVCT transitions cannot be rationalised with any plausible explanation at this point, however, it may be reasonable to believe that due to some heitherto unknown factors the intensity of the IVCT band reduces to such an extent which makes it difficult to be detected under the experimental conditions. Further explorations with newer molecules may thus be desirable.

\subsection{Unsymmetric ligand-bridged diruthenium} systems, $[\mathbf{1 1}]^{3+}$ and $[\mathbf{1 2}]^{+}$

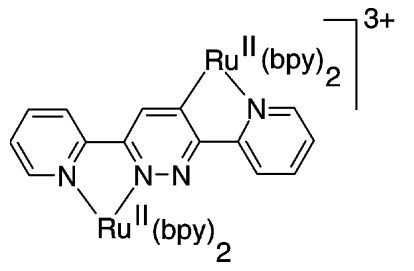

$\lceil 11\rceil^{3+}$

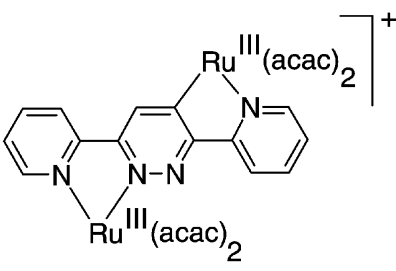

$\lceil 12\rceil^{+}$
In case of complexes, $[\mathbf{1 1}]^{3+}$ and $[\mathbf{1 2}]^{+}$, the ruthenium centres are unsymmetrically bridged via $\mathbf{B L}^{5}$ where one ruthenium ion is coordinated through neutral $\mathrm{N}, \mathrm{N}$ donor centres whereas the second ruthenium ion is bonded through cyclometallated $\mathrm{N}, \mathrm{C}^{-}$-donor centres of $\mathbf{B L} \mathbf{L}^{5}{ }^{14}$ Inspite of two electronically different ancillary ligand (AL) functions, $\pi$-acidic bpy $\left(\mathbf{A} \mathbf{L}^{7}\right)$ and electronically rich acac $\left(\mathbf{A} \mathbf{L}^{\mathbf{9}}\right)$ in $[\mathbf{1 1}]^{3+}$ and $[\mathbf{1 2}]^{+}$respectively, the $K_{c}$ values corresponding to the $\mathrm{Ru}^{\mathrm{II}} \mathrm{Ru}^{\mathrm{III}}$ mixed-valent state appear to be almost similar, $K_{c}: 1.4 \times 10^{8}$ and $3 \times 10^{8}$ for $[\mathbf{1 1}]^{3+}$ and $[\mathbf{1 2}]^{+}$ respectively. Both the complexes exhibit broad IVCT bands at the mixed-valent $\mathrm{Ru}^{\mathrm{II}} \mathrm{Ru}^{\mathrm{III}}$ state with similar features: $1335 \mathrm{~nm}\left(\varepsilon=2830 \mathrm{M}^{-1} \mathrm{~cm}^{-1}\right)$ and $\left.1295 \mathrm{~nm}\left(\varepsilon=1800 \mathrm{M}^{-1} \mathrm{~cm}^{-1}\right)\right]$. Thus, the effect of the electronic nature of ancillary ligands, bpy and acac, is not apparent. This implies that for $[\mathbf{1 1}]^{3+}$ and $[12]^{+}, K_{c}$ is a mere reflection of two parallely occurring factors: (i) donor-centre unsymmetry at each site of the metal ions, and (ii) bridging ligand-induced intermetallic coupling in the mixed-valent state. Since quantitative segmentations of the two parallel effects is rather difficult to make, therefore, the Hush formula is not applicable to such systems. However, the broad feature of the IVCT bands is suggestive of class II mixed-valent states. 
2.4 Trinuclear systems $[\mathbf{1 3}-\mathbf{1 5}]^{3+}$ and $\mathbf{1 6}$

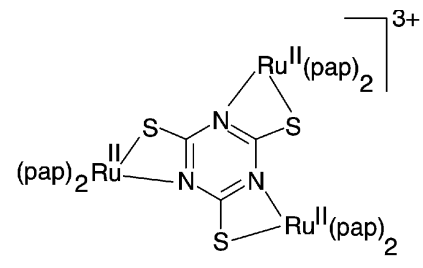

$[13]^{3+}$

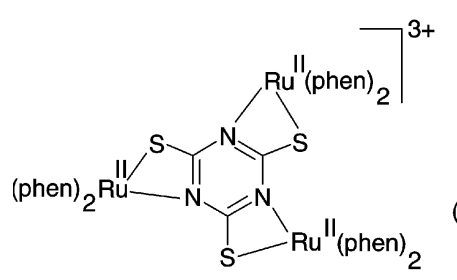

$[15]^{3+}$

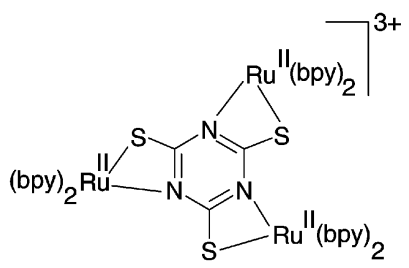

$[14]^{3+}$

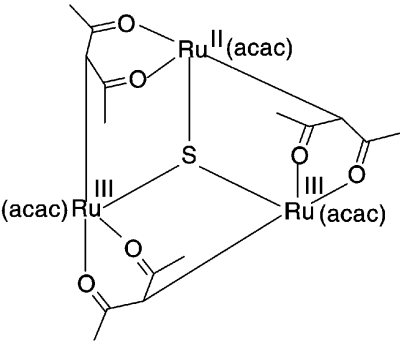

16
The symmetric trinuclear system is of special importance as it extends the access to two different mixedvalent states such as $\mathrm{Ru}^{\mathrm{II}} \mathrm{Ru}{ }^{\mathrm{II}} \mathrm{Ru}{ }^{\mathrm{III}}$ and $\mathrm{Ru}^{\mathrm{II}} \mathrm{Ru}{ }^{\mathrm{III}} \mathrm{Ru}{ }^{\mathrm{III}}$. $[13-15]^{3+}$ exhibit three successive $\mathrm{Ru}^{\mathrm{II}} \mathrm{Ru}^{\mathrm{III}}$ couples with moderate $K_{c}\left(K_{c 1} / K_{c 2}\right)$ values of $1.1 \times 10^{2.0} /$ $1 \cdot 1 \times 10^{3 \cdot 0}, 10^{3 \cdot 6} / 10^{4 \cdot 2}$ and $10^{3 \cdot 2} / 10^{4 \cdot 1}$ corresponding to $\mathrm{Ru}^{\mathrm{II}} \mathrm{Ru}^{\mathrm{II}} \mathrm{Ru}^{\mathrm{III}}\left(K_{c 1}\right)$ and $\mathrm{Ru}^{\mathrm{II}} \mathrm{Ru}^{\mathrm{III}} \mathrm{Ru}^{\mathrm{III}}\left(K_{c 2}\right)$ states respectively. ${ }^{15 \mathrm{a}, \mathrm{b}}$ On the other hand, $\mu_{3} \mathrm{~S}$ bridged complex 16 shows extensive electrochemical coupling of $K_{c 1}$ and $K_{c 2}, 10^{28} / 10^{12}$ respectively. ${ }^{15 c}$ Spectroelectrochemical studies on $[\mathbf{1 4}]^{3+}$ reveal that both the mixed-valent states $\mathrm{Ru}^{\mathrm{II}} \mathrm{Ru}^{\mathrm{II}} \mathrm{Ru}^{\mathrm{III}}$ and $\mathrm{Ru}{ }^{\mathrm{II}} \mathrm{Ru}{ }^{\mathrm{III}} \mathrm{Ru}{ }^{\mathrm{III}}$ have the same broad IVCT profiles, $\lambda_{\max }($ IVCT $)=$ $2000 \mathrm{~nm}\left(\varepsilon=2400 \mathrm{M}^{-1} \mathrm{~cm}^{-1}\right)$, typical of class II behaviour as is expected from the moderate $K_{c}$ values. Trinuclear mixed-valent complexes of this sort are expected to display two distinct IVCT transitions in the diradical form of $\mathrm{Ru}^{\mathrm{II}} \mathrm{Ru}^{\mathrm{III}} \mathrm{Ru}^{\mathrm{III}}$ as the magnetic exchange between the two one-electron paramagnetic $\mathrm{Ru}^{\text {III }}$ centres leads to two distinct electronic states depending on the mode of coupling between the $\mathrm{Ru}^{\mathrm{III}}$ centres, either antiferromagnetic or ferromagnetic. However, the expected effect could not be detected possibly due to the smaller amplitude of this effect with respect to broadening of the experimentally obtained IVCT band by the non-degeneracy of the $d$-orbitals of the metal ion.

\subsection{Ligand-bridged $R u^{I I I} R u^{I I I}$ dimer, 17-21}

Ligand-bridged $\mathrm{Ru}^{\mathrm{III}} \mathrm{Ru}^{\mathrm{III}}$ dimers 17-21 show two successive one-electron oxidation and reduction processes. ${ }^{16}$ Separations in potentials for the oxidation
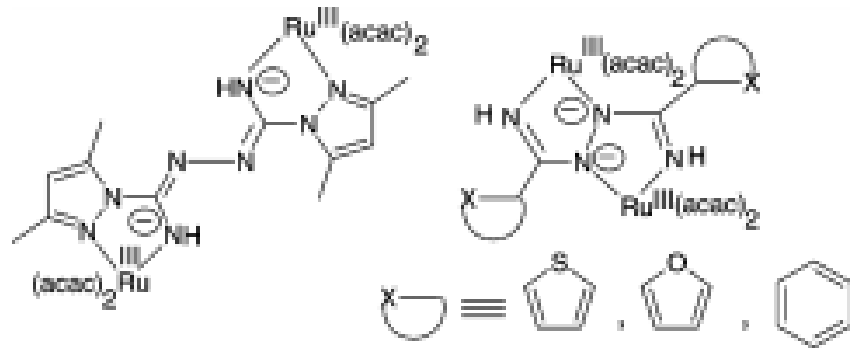

17

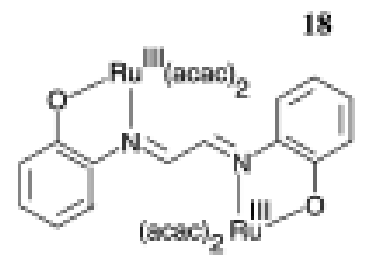

19

20

$\left(K_{c 1}\right)$ and reduction $\left(K_{c 2}\right)$ processes translate to the $K_{c}$ values of $10^{12} / 1 \cdot 1 \times 10^{6}, 10^{12 \cdot 9} / 10^{12 \cdot 8}, 10^{12 \cdot 9} / 10^{13 \cdot 2}$, $10^{13.0} / 10^{13.2}$ and $1.7 \times 10^{6} / 2.7 \times 10^{8}$ for $17, \mathbf{1 8}, \mathbf{1 9}, \mathbf{2 0}$ and 21 respectively. Ruthenium ions being in the +3 state in 17-21, it is tempting to assign the redox processes corresponding to $\mathrm{Ru}^{\mathrm{III}} \mathrm{Ru}^{\mathrm{IV}}$ and $\mathrm{Ru}{ }^{\mathrm{II}} \mathrm{Ru}{ }^{\mathrm{III}}$ couples. In 17, the oxidation and reduction couples are indeed assigned as $\mathrm{Ru}^{\mathrm{IV}} \rightleftharpoons \mathrm{Ru}^{\mathrm{III}}$ and $\mathrm{Ru}^{\mathrm{III}} \rightleftharpoons \mathrm{Ru}^{\mathrm{II}}$ processes respectively. The electrochemically generated $\mathrm{Ru}^{\mathrm{II}} \mathrm{Ru}^{\mathrm{III}}$ mixed-valent intermediate $[\mathbf{1 7}]^{-}$, exhibits moderately intense IVCT band at $2360 \mathrm{~nm}$ ( $\varepsilon=11300 \mathrm{M}^{-1} \mathrm{~cm}^{-1}$ ) and $\Delta v_{1 / 2}$ (calculated) $3128 \mathrm{~cm}^{-1}$ is smaller than $\Delta v_{1 / 2}$ (experimental), $1800 \mathrm{~cm}^{-1}$. Therefore, taking $K_{c}$ and IVCT chracteristics into consideration, the $\mathrm{Ru}^{\mathrm{II}} \mathrm{Ru}^{\mathrm{III}}$ state has been assigned to the strongly coupled class II state approaching class III. Though $\mathrm{Ru}^{\mathrm{III}} \mathrm{Ru}^{\mathrm{IV}}$ state in $[\mathbf{1 7}]^{+}$exhibits large $K_{c}$ values of $10^{12}$, it fails to show any IVCT band up to $3000 \mathrm{~nm}$.

On the other hand, in 18-20 encompassing noninnocent bridging ligands $\left[\mathbf{B L}^{\mathbf{8 - 1 0}}\right]^{2-}$ (scheme 1$)$ the situations with respect to accessible electron-transfer processes are altogether different. Oxidation processes take place at the bridging ligand site leading to the formation of $\left[\left(\mathbf{A L}^{9}\right)_{2} \mathrm{Ru}^{\text {III }}\left(\mu-\mathbf{B L}^{\mathbf{8 - 1 0}}\right)^{2-} \mathrm{Ru}^{\mathrm{III}}\right.$ $\left.\left(\mathbf{A} \mathbf{L}^{\mathbf{9}}\right)_{2}\right] \rightarrow\left[\left(\mathbf{A} \mathbf{L}^{\mathbf{9}}\right)_{2} \mathrm{Ru}^{\mathrm{III}}\left(\boldsymbol{\mu}-\mathbf{B} \mathbf{L}^{\mathbf{8 - 1 0}}\right)^{\bullet-} \mathrm{Ru}^{\mathrm{III}}\left(\mathbf{A} \mathbf{L}^{\mathbf{9}}\right)_{2}\right]^{+} \rightarrow$

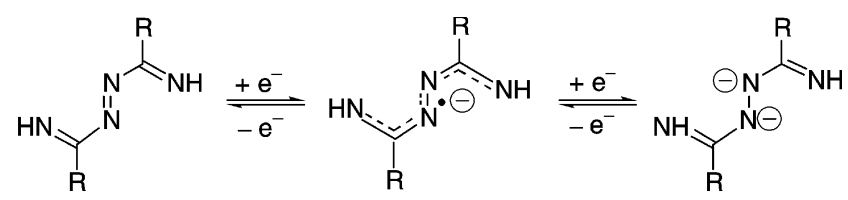
BL $^{8-10}$
$\left[\mathrm{BL}^{8-10}\right]^{\bullet-}$
$\left[\mathrm{BL}^{8-10}\right]^{2-}$

Scheme 1. 
<smiles>O=C1C=CC=CC1=NC=CN=C1C=CC=CC1=O</smiles>

Scheme 2.

$\left[\left(\mathbf{A} \mathbf{L}^{9}\right)_{2} \mathrm{Ru}^{\mathrm{III}}\left(\mu-\mathbf{B} \mathbf{L}^{\mathbf{8 - 1 0}}\right) \mathrm{Ru}^{\mathrm{III}}\left(\mathbf{A L}^{\mathbf{9}}\right)_{2}\right]^{2+}$, whereas the reduction processes yield seemingly paradoxical redox redistributions to $\left[\left(\mathbf{A L}^{\mathbf{9}}\right)_{2} \mathrm{Ru}^{\mathrm{III}}\left(\mu-\mathbf{B L}^{\mathbf{8 - 1 0}}\right)^{2-} \mathrm{Ru}^{\text {III }}\right.$ $\left.\left(\mathbf{A L}{ }^{9}\right)_{2}\right] \rightarrow\left[\left(\mathbf{A L}^{9}\right)_{2} \mathrm{Ru}^{\mathrm{II}}\left(\boldsymbol{\mu}-\mathbf{B L}^{\mathbf{8 - 1 0}}\right)^{-} \mathrm{Ru}^{\mathrm{II}}\left(\mathbf{A} \mathbf{L}^{9}\right)_{2}\right]^{-} \rightarrow$ $\left[\left(\mathbf{A L}^{9}\right)_{2} \mathrm{Ru}^{\mathrm{II}}\left(\mu-\mathbf{B L} \mathbf{L}^{\mathbf{8}-10}\right)^{2-} \mathrm{Ru}^{\mathrm{II}}\left(\mathbf{A L}^{9}\right)_{2}\right]^{2-}$.

In 21, though the bridging ligand $\left[\mathbf{B L}^{11}\right]^{2-}$ is similarly susceptible to undergo successive two oneelectron oxidation and reduction processes (scheme 2 ), experimental results in combination with DFT calculations have established metal based $\mathrm{Ru}^{\mathrm{III}} / \mathrm{Ru}^{\mathrm{IV}}$ oxidation and $\left[\mathbf{B L}^{\mathbf{1 1}}\right]^{2-}$ based reduction processes.

The mixed-valent $\mathrm{Ru}^{\mathrm{III}} \mathrm{Ru}^{\mathrm{IV}}$ state in $[\mathbf{2 1}]^{+}$, exhibits a nice IVCT band at $1795 \mathrm{~nm}\left(\varepsilon=2500 \mathrm{M}^{-1} \mathrm{~cm}^{-1}\right)$ and the analysis of the IVCT band suggests its borderline class II-III behaviour. It should be pointed out that $[\mathbf{2 1}]^{+}$demonstrates the first example where distinct IVCT transition corresponding to $\mathrm{Ru}^{\mathrm{III}} \mathrm{Ru}^{\mathrm{IV}}$ state has been detected, though many reports on $\mathrm{Ru}^{\mathrm{II}} \mathrm{Ru}{ }^{\mathrm{III}}$ mixed-valent state are available.

\subsection{Role of ancillary ligands towards the selection} of electron-transfer sites in ligand-bridged diruthenium systems, $[\mathbf{2 2 - 2 6}]^{n+}$

The combination of dianionic $\left[\mathbf{B} \mathbf{L}^{\mathbf{1 2}}\right]^{2-}$ as bridging ligand and acac $\left(\mathbf{A} \mathbf{L}^{\mathbf{9}}\right)$ as ancillary ligand develops the $\mathrm{Ru}^{\mathrm{III}} \mathrm{Ru}^{\mathrm{III}}$ dimer, 22, whereas alternative combinations of $\pi$-acidic bpy $\left(\mathbf{A} \mathbf{L}^{7}\right) /\left[\mathbf{B} \mathbf{L}^{12}\right]^{2-}$ and strongly $\pi$-acidic pap $\left(\mathbf{A L} \mathbf{L}^{\mathbf{1}}\right) /\left[\mathbf{B} \mathbf{L}^{\mathbf{1 2}}\right]^{2-}$, lead to $\mathrm{Ru}^{\mathrm{II}} \mathrm{Ru}^{\mathrm{II}}$ dimers, $[\mathbf{2 3}]^{2+}$ and $[\mathbf{2 4}]^{2+}$ respectively. ${ }^{17 a}$ The complexes exhibit two successive one-electron oxidation and one-

(i)

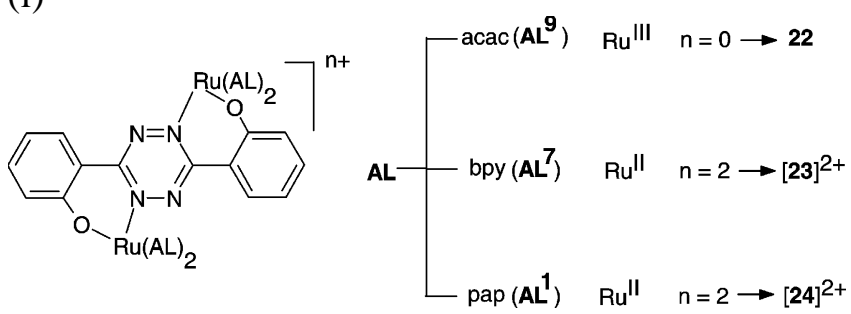

electron reduction processes with $K_{c}$ values, $7.9 \times 10^{3}$ $\left(K_{c 1}\right) / 1 \cdot 1 \times 10^{12}\left(K_{c 2}\right), 1 \cdot 3 \times 10^{6}\left(K_{c 1}\right) / 1 \cdot 3 \times 10^{17}\left(K_{c 2}\right)$ and $3.5 \times 10^{2}\left(K_{c 1}\right) / 6.2 \times 10^{7}\left(K_{c 2}\right)\left(K_{c 1}\right.$ is related to oxidation processes and $K_{c 2}$ is related to reduction processes) for $22[\mathbf{2 3}]^{2+}$ and $[\mathbf{2 4}]^{2+}$ respectively. Standard reductions of bpy above $-1.5 \mathrm{~V}$ vs SCE have not been taken into consideration at present. The oxidation processes in $\mathbf{2 2}$ are assigned as $\mathrm{Ru}^{\mathrm{III}} \mathrm{Ru}^{\mathrm{IV}}$ couples whereas the reduction processes either could be exclusively $\mathrm{Ru}^{\mathrm{II}} \mathrm{Ru}^{\mathrm{III}}$ processes or mixed tetrazine $\left(\left[\mathbf{B L}^{\mathbf{1 2}}\right]^{2-}\right)$ and $\mathrm{Ru}^{\mathrm{III}}$ based processes. The case of bpy complex, $[\mathbf{2 3}]^{2+}$, is much simpler, oxidations are associated with the $\mathrm{Ru}^{\mathrm{II}} \mathrm{Ru}^{\mathrm{III}}$ processes and reductions involve the tetrazine ring. In case of pap-based dimer, $[24]^{2+}$, the reductions are associated either with the pap or tetrazine whereas first oxidation process surprisingly involves the orbitals associated with the phenoxy group of $\left[\mathbf{B L}^{\mathbf{1 2}}\right]^{2-}$ instead of usually expected $\mathrm{Ru}^{\mathrm{II}}$ centre, leading to the formation of unusual $\mathrm{Ru}^{\mathrm{II}} \mathrm{Ru} \mathrm{u}^{\mathrm{II}}$-phenoxide radical species. The reduction processes are associated either with pap or tetrazinebased orbitals.

(ii)

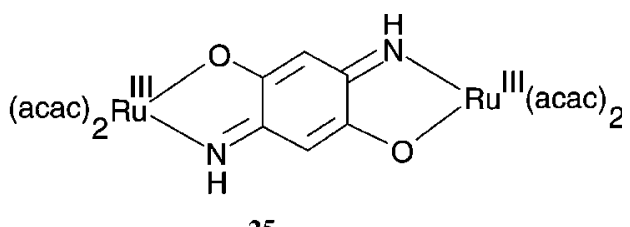

25

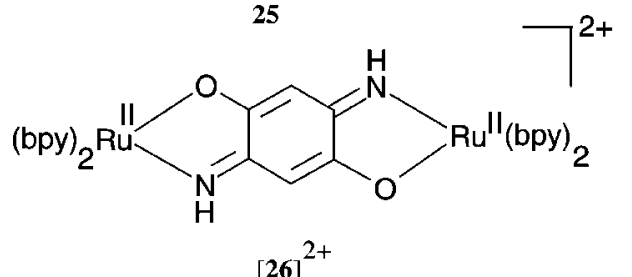

$[26]^{2+}$

Similarly, the combinations of $\left[\mathbf{B} \mathbf{L}^{\mathbf{1 3}}\right]^{2-}$ bridging ligand with acac $\left(\mathbf{A L}^{\mathbf{9}}\right)$ and bpy $\left(\mathbf{A} \mathbf{L}^{\mathbf{7}}\right)$ as ancillary ligands stabilise the ruthenium ions in +3 and +2 
states in $\mathbf{2 5}$ and $[\mathbf{2 6}]^{2+}$, respectively. ${ }^{17 \mathrm{~b}}$ Complexes 25 and $[\mathbf{2 6}]^{2+}$ exhibit two successive oxidation and reduction processes with $K_{c}$ values of $2.1 \times 10^{10}$ $\left(K_{c 1}\right), 7.3 \times 10^{11}\left(K_{c 2}\right)$ and $6.5 \times 10^{8}\left(K_{c 1}\right), 2 \times 10^{8}\left(K_{c 2}\right)$ respectively. Since both the bridging ligand, $\left[\mathbf{B L}{ }^{\mathbf{1 3}}\right]^{2-}$ and ruthenium centres in $\mathbf{2 5}$ and $\mathbf{2 6}^{2+}$ are susceptible to undergo successive oxidation and reduction processes as shown in scheme 3, therefore, the challenge involves establishing the involvement of bridging ligand or ruthenium ion in the accessible redox processes.

\section{At the metal site:}

$$
\begin{aligned}
& \mathrm{Ru}^{\mathrm{III}} \mathrm{Ru}^{\mathrm{III}} \stackrel{\text { ox1 }}{\rightleftharpoons} \mathrm{Ru}^{\mathrm{III}} \mathrm{Ru}^{\mathrm{IV}} \text {, and } \\
& \mathrm{Ru}^{\mathrm{III}} \mathrm{Ru}^{\mathrm{IV}} \stackrel{\text { ox2 }}{=} \mathrm{Ru}^{\mathrm{IV}} \mathrm{Ru}^{\mathrm{IV}}, \\
& \mathrm{Ru}^{\mathrm{III}} \mathrm{Ru}{ }^{\mathrm{III}} \stackrel{\text { redl }}{\rightleftharpoons} \mathrm{Ru}^{\mathrm{III}} \mathrm{Ru}^{\mathrm{II}} \text {, and } \\
& \mathrm{Ru}^{\mathrm{III}} \mathrm{Ru} \stackrel{\text { red2 }}{\rightleftharpoons} \mathrm{Ru}^{\mathrm{II}} \mathrm{Ru}^{\mathrm{II}},
\end{aligned}
$$

and

At the $\left[\boldsymbol{B} \boldsymbol{L}^{13}\right]^{2-}$ site:
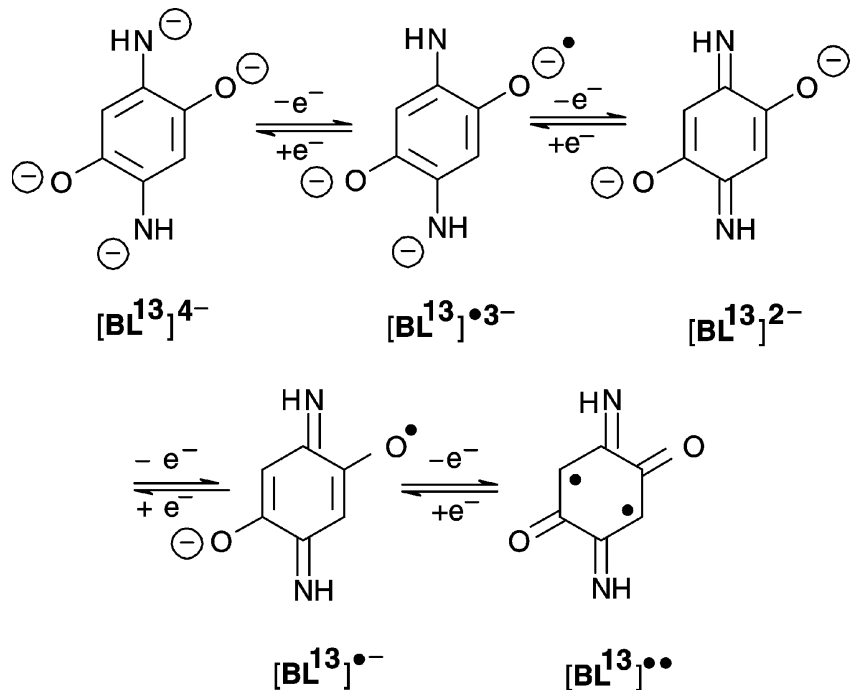

Scheme 3.

Detailed structural, spectroelectrochemical and EPR studies in combination with DFT calculations in each redox state for both the complexes suggest that in case of $\mathbf{2 5}$, oxidation processes involve the metal ion passing through the mixed-valent $\mathrm{Ru}^{\mathrm{III}} \mathrm{Ru}^{\mathrm{IV}}$ intermediate state whereas the reduction processes are preferentially centred around the $\left[\mathbf{B} \mathbf{L}^{13}\right]^{2-}$ leading to the three-spin $\left[\mathrm{Ru}^{\mathrm{III}}\left\{\left(\mathbf{B L}^{\mathbf{1 3}}\right)^{\bullet 3-}\right\} \mathrm{Ru}^{\mathrm{III}}\right]$ intermediate. However, in case of bpy complex $[\mathbf{2 6}]^{2+}$ the bridging ligand-based orbitals are primarily involved in both oxidation and reduction processes.

\subsection{Effect of structurally similar but electronically} different bridging ligands under a particular ancillary ligand towards the metal-ligand valence state distribution in $\mathbf{2 7}$ and $\mathbf{2 8}$

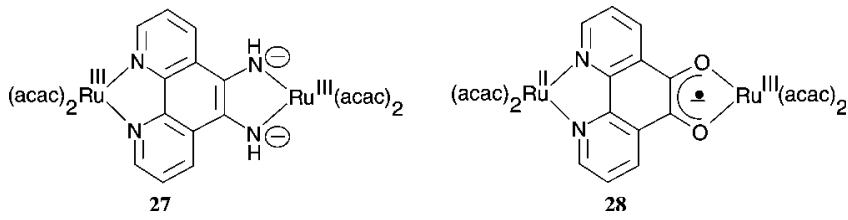

In an environment of acac as ancillary ligand $\left(\mathbf{A} \mathbf{L}^{\mathbf{9}}\right)$, complexes $\mathbf{2 7}$ and $\mathbf{2 8}$ differ with respect to the nature of the redox non-innocent bridging ligands 1,10phenthroline-5,6-diimine (BL $\left.\mathbf{B L}^{\mathbf{1 4}}\right)$ and 1,10-phenthroline-5,6-dione $\left(\mathbf{B L}^{\mathbf{1 5}}\right)$, respectively. ${ }^{18}$ The more basic character of diimine-based bridging ligand $\left(\mathbf{B L}^{\mathbf{1 4}}\right)$ with respect to the dione-based bridging ligand $\left(\mathbf{B L}^{15}\right)$ stabilises the ruthenium centres in +3 states in 27 where BL exists in the dianionic iminocate-

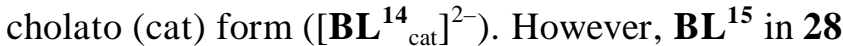
stabilises in the semiquinone (sq) state $\left(\left[\mathbf{B L}^{15}{ }_{\mathrm{sq}}\right]^{\circ-}\right)$ yielding mixed-valent $\mathrm{Ru}^{\mathrm{II}} \mathrm{Ru}^{\mathrm{III}}$ species in the native state. Detailed analysis of the elctron transfer properties reveal that as in the native state, the metalligand valence state combination also differs in their first reduced state, leading to the resultant metalbridging ligand-metal configurations of $\left[\mathrm{Ru}^{\mathrm{II}}\right.$ $\left.\left\{\left(\mathbf{B L}^{14}{ }_{\mathrm{sq}}\right)^{\bullet-}\right\} \mathrm{Ru}^{\mathrm{II}}\right]^{-}$and $\left[\mathrm{Ru}^{\mathrm{II}}\left\{\left(\mathbf{B L}^{15}{ }_{\text {cat }}\right)^{2-}\right\} \mathrm{Ru}^{\mathrm{III}}\right]^{-}$in $[27]^{-}$and $[\mathbf{2 8}]^{-}$respectively. However, the second reduced state and the successive oxidation processes behave identically for both the complexes.

\subsection{Metal-ligand valence state distribution in diruthenium quinonoid system, 29}

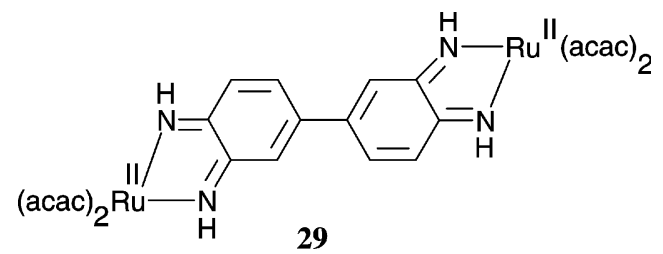

Complex 29 can, in principle, be stabilised in any of the possible five valence tautomeric forms: $\left[\mathrm{Ru}^{\mathrm{IV}}\left\{\left(\mathbf{B L}^{\mathbf{1 6}}{ }_{\text {Cat-Cat }}\right)^{4-}\right\} \mathrm{Ru}^{\mathrm{IV}}\right] \leftrightarrow\left[\mathrm{Ru}^{\mathrm{IV}}\left\{\left(\mathbf{B L}^{\mathbf{1 6}}{ }_{\mathrm{Cat}-\mathrm{Sq}}\right)^{3-}\right\}\right.$ $\left.\mathrm{Ru}^{\text {III }}\right] \leftrightarrow\left[\operatorname{Ru}^{\text {III }}\left\{\left(\mathbf{B L}^{16}{ }_{\text {Sq-Sq }}\right)^{2-}\right\} \operatorname{Ru}^{\text {III }}\right] \leftrightarrow\left[\operatorname{Ru}^{\text {III }}\left\{\left(\mathbf{B L}^{16}{ }_{\text {Sq-Q }}\right)^{-}\right\}\right.$ $\left.\mathrm{Ru}^{\mathrm{II}}\right] \leftrightarrow\left[\mathrm{Ru}^{\mathrm{II}}\left(\mathbf{B L}^{16}{ }_{\mathrm{Q}-\mathrm{Q}}\right) \mathrm{Ru}^{\mathrm{II}}\right]$ as both the metal ion and the bridging ligand $\left(\mathbf{B L} \mathbf{L}^{\mathbf{1 6}}\right)$ are susceptible to 
participate in redox chain processes. Our experimental evidences justify the preferential formulation of $\left[\mathrm{Ru}^{\mathrm{II}}\left(\mathbf{B L}^{\mathbf{1 6}}{ }_{\mathrm{Q}-\mathrm{Q}}\right) \mathrm{Ru}^{\mathrm{II}}\right]$ for $29 .{ }^{19}$ The complex 29 shows two oxidation processes corresponding to $\mathrm{Ru}^{\mathrm{II}} \mathrm{Ru}^{\mathrm{III}}$ couples $\left(K_{c} \sim 10^{3}\right)$ and successive bridging ligand based reduction processes $\left(\mathbf{B L}^{16}{ }_{\mathrm{Q}-\mathrm{Q}}\right) \rightarrow\left(\mathbf{B L}^{16}{ }_{\mathrm{Q}-\mathrm{Sq}}\right)^{{ }^{-}} \rightarrow$ $\left(\text { BL }^{16}{ }_{\mathrm{Sq}-\mathrm{Sq}}\right)^{2-}$. The mixed-valent $\mathrm{Ru}^{\mathrm{II}} \mathrm{Ru}^{\mathrm{III}}$ state exhibits rhombic EPR spectrum and a weak IVCT transition at $1570 \mathrm{~nm} \quad\left(\varepsilon=800 \mathrm{M}^{-1} \mathrm{~cm}^{-1}\right)$ with $\Delta v_{1 / 2 \text { calcld, }}$ $3836 \mathrm{~cm}^{-1}$ and $\Delta v_{1 / 2}$ exptal, $1200 \mathrm{~cm}^{-1}$. The narrow feature of IVCT signifies its class II-III borderline situation. The one-electron reduced species i.e. $\left[\mathrm{Ru}^{\mathrm{II}}\left(\mathbf{B L}^{16}{ }_{\mathrm{Q}-\mathrm{Sq}}\right)^{{ }^{-}} \mathrm{Ru}^{\mathrm{II}}\right]^{-}, \quad[29]^{-}$, however, shows one free radical EPR signal and intense low-energy transition at $2160 \mathrm{~nm}\left(\varepsilon=4000 \mathrm{M}^{-1} \mathrm{~cm}^{-1}\right)$ corresponding to $\mathrm{Sq} \rightarrow \mathrm{Q}$ intra-ligand intervalence transition.

\subsection{Stabilisation of spin-coupled mixed-valent} $R u^{I I} R u^{I I I}$ dimer in conjunction with azo-anion radical based bridging ligand, $\mathbf{3 0}$

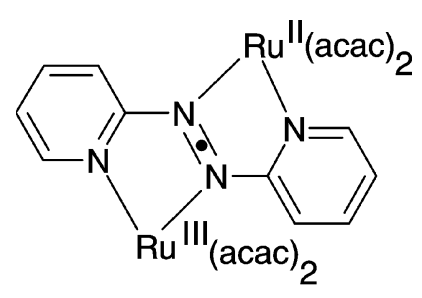

30

Complex 30 demonstrates a unique example where the mixed-valent $\mathrm{Ru}^{\mathrm{II}} \mathrm{Ru}^{\mathrm{III}}$ state has been stabilised under an environment of radical anion form of $\left[\mathbf{B L}{ }^{17}\right]^{\bullet-}$ and acac as $\mathbf{A} \mathbf{L}^{\mathbf{9}} \cdot{ }^{20}$ Moreover, the unpaired spins associated with the metal ion $\left(\mathrm{Ru}^{\mathrm{III}}\right)$ and the azo-radical anion are in spin-coupled singlet state. The azo-radical state of coordinated $\mathbf{B L}^{\mathbf{1 7}}$ in $\mathbf{3 0}$ has been evidenced via $\mathrm{N}, \mathrm{N}$ bond distances: $m e s o$-form, $1.374 \AA$ (DFT data: $1.349 \AA$ ) and $r a c$-form, $1.365 \AA$ (DFT data: 1.344 A). The detailed spectroelectrochemical and EPR studies justify the involvement of metal-based frontier orbitals instead of $\left[\mathbf{B L}^{17}\right]^{\bullet-}$ in the accessible electron-transfer processes.

\section{Conclusions}

The present discussion with a wide variety of molecular frameworks establish that in addition to the bridging ligand, the electronic aspects of the ancillary ligand can also impose a serious impact on the intermetallic coupling processes in the polyruthenium systems. The establishment of mixed-valence characteristics based on either electrochemical $\left(K_{c}\right)$ or IVCT (intervalence charge transfer transition) features may lead to confusion in many occasions, particularly in the borderline class II-class III situation. Moreover, the presence of non-innocent bridging function introduces additional complications with respect to the involvements of the metal or ligand or mixed metal-ligand based frontier molecular orbitals in redox processes. Therefore, the use of electrochemistry in combination with electronic spectral profiles, particularly at the long wavelength region (NIR/IR) and EPR studies for the intermediate paramagnetic states along with structural aspects and high level theoretical calculations can only offer better perceptions. The present exercise further highlights the need for designing newer molecules in greater numbers to obtain better insights with the help of advanced experimental and theoretical studies.

\section{Acknowledgements}

Financial support received from the Department of Science and Technology (DST), Govt. of India and Council of Scientific and Industrial Research (CSIR), New Delhi is gratefully acknowledged. We are also grateful to Prof M D Ward, of the University of Bristol, UK, Prof Wolfgang Kaim, of the Universität Stuttgart, Germany, and to Drs Nripen Chanda, Biprajit Sarkar, Srikanta Patra, Sanjib Kar and Somnath Maji for their active contributions to the work.

\section{References}

1. (a) Kaim W, Klein A and Glöckle M 2000 Acc. Chem. Res. 33 755; (b) Ward M D 1995 Chem. Soc. Rev. 24 121; (c) McCleverty J A and Ward M D 1998 Acc. Chem. Res. 31 842; (d) Crutchley R J 2004 Comprehensive coordination chemistry II (eds) J A McCleverty and T J Meyer vol 2, p. 235; (e) Hupp, J T 2004 Comprehensive coordination chemistry II (eds) J A McCleverty and T J Meyer vol 2, p. 709; (f) Breedlove B K, Yamaguchi T, Ito T, Londergan C H and Kubiak C P 2004 Comprehensive coordination chemistry II (eds) J A McCleverty and T J Meyer vol 2, p. 717; (g) Giuffrida G and Campagna S 1994 Coord. Chem. Rev. 135-136 517; (h) Brunschwig B S, Creutz C and Sutin N 2002 Chem. Soc. Rev. 31 168

2. (a) Creutz C and Taube H 1969 J. Am. Chem. Soc. 91 3988; (b) Creutz C and Taube H 1973 J. Am. Chem. Soc. 951086

3. (a) Balzani V, Venturi M and Credi A 2003 Molecular devices and machines: A journey into the nano- 
world (Weinheim: Wiley-VCH); (b) Feringa B L (ed.) 2001 Molecular switches (Weinheim: WileyVCH); (c) Paul F and Lapinte C 1998 Coord. Chem. Rev. 178-180 431; (d) Ward M D 1997 Chem. Ind. 640; (e) Ward M D 1996 Chem. Ind. 568; (f) Kahn O and Launay J-P 1988 Chemtronics 3 140; (g) Fraysse $\mathrm{S}$, Coudret C and Launay J-P $2003 \mathrm{~J}$. Am. Chem. Soc. 125 5880; (h) Fraysse S, Coudret C and Launay J-P 2000 Eur. J. Inorg. Chem. 7 1581; (i) Ward M D 2001 J. Chem. Edn. 78 321; (j) Joulié L F, Schatz E, Ward M D, Weber F and Yellowlees L J $1994 J$. Chem. Soc., Dalton Trans. 799

4. Solomon E I, Brunold T C, Davis M I, Kemsley J N, Lee S K, Lehnert N, Neese F, Skulan A J, Yang Y S and Zhou J 2000 Chem. Rev. 100235

5. (a) Brunschwig B S and Sutin N 1999 Coord. Chem. Rev. 187 233; (b) Bencini A, Ciofini I, Daul C A and Ferretti A 1999 J. Am. Chem. Soc. 12111418

6. (a) Chakraborty S, Laye R H, Paul R L, Gonnade R G, Puranik V G, Ward M D and Lahiri G K $2002 \mathrm{~J}$. Chem. Soc., Dalton Trans. 1172; (b) Chakraborty S, Laye R H, Munshi P, Paul R L, Ward M D and Lahiri G K 2002 J. Chem. Soc., Dalton Trans. 2348; (c) Sarkar B, Kaim W, Klein A, Schwederski B, Fiedler J, Duboc-Toia C and Lahiri G K 2003 Inorg. Chem. 42 6172, and references therein

7. Robin M B and Day P 1967 Adv. Inorg. Chem. Radiochem. 10247

8. Creutz C 1983 Prog. Inorg. Chem. 301

9. (a) Richardson D E and Taube H 1984 Coord. Chem. Rev. 60 107; (b) Evans C E B, Naklicki M L, Rezvani A R, White C A, Kondratiev V V V and Crutchley R J 1998 J. Am. Chem. Soc. 120 13096; (c) Barriere F, Camire N, Geiger W E, Mueller-Westerhoff U T and Sanders R 2002 J. Am. Chem. Soc. 124 7262; (d) Brunschwig B S and Sutin N 1999 Coord. Chem. Rev. 187 233; (e) Brown G M and Sutin N 1979 J. Am. Chem. Soc. 101883

10. (a) Hush N S 1985 Coord. Chem. Rev. 64 135; (b) Hush N S 1967 Progr. Inorg. Chem. 8391

11. (a) Al-Noaimi M, Yap G P A and Crutchley R J 2004 Inorg. Chem. 43 1770; (b) Demadis K D, Hartshorn C $\mathrm{M}$ and Meyer T J 2001 Chem. Rev. 1012655

12. (a) Chanda N, Laye R H, Chakraborty S, Paul R L, Jeffery J C, Ward M D and Lahiri G K 2002 J. Chem.
Soc., Dalton Trans. 3496; (b) Chanda N, Sarkar B, Kar S, Fiedler J, Kaim W and Lahiri G K 2004 Inorg. Chem. 43 5128; (c) Chanda N, Sarkar B, Fiedler J, Kaim W and Lahiri G K 2003 Dalton Trans. 3550

13. (a) Sarkar B, Laye R H, Mondal B, Chakraborty S, Paul R L, Jeffery J C, Puranik V G, Ward M D and Lahiri G K 2002 J. Chem. Soc., Dalton Trans. 2097; (b) Patra S, Sarkar B, Ghumaan S, Fiedler J, Kaim W and Lahiri G K 2004 Inorg. Chem. 43 6108; (c) Ghumaan S, Kar S, Mobin S M, Harish B, Puranik V G and Lahiri G K 2006 Inorg. Chem. 45 2413; (d) Patra S, Sarkar B, Ghumaan S, Fiedler J, Kaim W and Lahiri G K 2004 Dalton Trans. 754

14. Ghumaan S, Sarkar B, Patra S, Parimal K, van Slageren J, Fiedler J, Kaim and Lahiri G K 2005 Dalton Trans. 706

15. (a) Kar S, Pradhan B, Sinha R K, Kundu T, Kodgire P, Rao K K, Puranik V G and Lahiri G K 2004 Dalton Trans. 1752; (b) Kar S, Miller T A, Chakraborty S, Sarkar B, Pradhan B, Sinha R K, Kundu T, Ward M D and Lahiri G K 2003 Dalton Trans. 2591; (c) Patra S, Mondal B, Sarkar B, Niemeyer M and Lahiri G K 2003 Inorg. Chem. 421322

16. (a) Patra S, Miller T A, Sarkar B, Niemeyer M, Ward M D and Lahiri G K 2003 Inorg. Chem. 42 4707; (b) Maji S, Sarkar B, Patra S, Fiedler J, Mobin S M, Puranik V G, Kaim W and Lahiri G K 2006 Inorg. Chem. 45 1316; (c) Kar S, Sarkar B, Ghumaan S, Roy D, Urbanos F A, Fiedler J, Sunoj R B, JimenezAparicio R, Kaim W and Lahiri G K 2005 Inorg. Chem. 448715

17. (a) Patra S, Sarkar B, Maji S, Fiedler J, Urbanos F A, Jimenez-Aparicio R, Kaim W and Lahiri G K 2006 Chem. Eur. J. 12 489; (b) Kar S, Sarkar B, Ghumaan S, Janardanan D, van Slageren J, Fiedler J, Puranik V G, Sunoj R B, Kaim W and Lahiri G K 2005 Chem. Eur. J. 114901

18. Ghumaan S, Sarkar B, Patra S, van Slageren J, Fiedler J, Kaim W and Lahiri G K 2005 Inorg. Chem. 44 3210

19. Patra S, Sarkar B, Ghumaan S, Fiedler J, Zalis S, Kaim W and Lahiri G K 2004 Dalton Trans. 750

20. Sarkar B, Patra S, Fiedler J, Sunoj R B, Janardanan D, Mobin S M, Niemeyer M, Lahiri G K and Kaim W 2005 Angew. Chem., Int. Ed. 445655 